\title{
Stage IA Lung Cancer AJCC v7
}

National Cancer Institute

\section{Source}

National Cancer Institute. Stage IA Lung Cancer A/CC v7. NCI Thesaurus. Code C5642.

Stage IA includes: (T1a, N0, M0); (T1b, NO, M0). T1a: Lung cancer with a tumor size of 2 $\mathrm{cm}$ or less in greatest dimension, surrounded by lung or visceral pleura and without bronchoscopic evidence of invasion more proximal than the lobar bronchus (i.e., not in the main bronchus). The uncommon superficial tumor of any size with its invasive component limited to the bronchial wall, which may extend proximal to the main bronchus, is also classified as T1a. T1 b: Lung cancer with a tumor size more than $2 \mathrm{~cm}$ but $3 \mathrm{~cm}$ or less in greatest dimension, surrounded by lung or visceral pleura and without bronchoscopic evidence of invasion more proximal than the lobar bronchus (i.e., not in the main bronchus). N0: No regional lymph metastasis. M0: No distant metastasis. (AJCC 7th ed.) 